\section{Prevalence, Molecular Epidemiology and Drug Resistance Pattern of Human Immunodeficiency Virus Type 1 among Injecting Drug Users in Lahore, Pakistan}

\author{
Saima Yaqub ${ }^{1}$, Tahir Yaqub ${ }^{1 *}$, Muhammad Zubair Shabbir ${ }^{2}$, Asif Nadeem \\ Aziz-Ul-Rahman ${ }^{1}$, Muhammad Furqan Shahid ${ }^{1}$, Zarfishan Tahir ${ }^{4}$ and \\ Nadia Mukhtar ${ }^{4}$ \\ ${ }^{1}$ Department of Microbiology, University of Veterinary and Animal Sciences, Lahore, \\ Pakistan \\ ${ }^{2}$ Quality Operations Laboratory, University of Veterinary and Animal Sciences, Lahore, \\ Pakistan \\ ${ }^{3}$ Institute of Biochemistry and Biotechnology, University of Veterinary and Animal \\ Sciences, Lahore, Pakistan \\ ${ }^{4}$ Director General Health Services, Primary and Secondary Health Care Department, \\ Government of Punjab, Pakistan
}

\begin{abstract}
A B S T R A C T
Human immunodeficiency virus 1 (HIV-1) is common among injecting drug users (IDUs), and HIV1 positive IDUs may have potential of HIV transmission among general population through different ways. Therefore, an understanding towards current status of HIV prevalence and genomic characteristics of circulating strains is crucial to devise and implement necessary interventions to control disease in developing countries like Pakistan. A total of 201 plasma samples were collected from IDUs. Samples were first screened using HIV-1 Ag/Ab Combo test and then antigen positive samples were amplified for HIV-1 pol gene (1084 bp) and analyzed. Initial screening showed a total of 49 HIV samples positive (24.37\%; 95\% CI: 18.96-30.76). A substantial association of HIV incidence was observed in individuals with HCV infection $(36.84 \%$; $95 \%$ CI: $28.55-45.99 ; p<0.0001)$ followed by individuals involved in practices of shared injection equipment $(21.17 \%$; $95 \%$ CI: $25.07-40.21 ; p<0.0001)$, injected previously used syringes (30.2\%; 95\% CI: 23.4-37.99; $p=0.0016)$, sex with IDUs (37.78\%; 95\% CI: 25.11-52.37; $p=0.002)$ and those with an age between $30-39$ years $(27.17 \%$; $95 \%$ CI: $19.13-37.04 ; p=0.039)$. The $p o l$ gene-based phylogeny and subtyping classification categorized the under-study sequences representing subtype A $(n=12 ; 46.15 \%)$, CRF02 AG $(n=6 ; 23.08 \%)$, subtype $C(n=5 ; 19.23 \%)$ and subtype $G(n$ $=3 ; 11.54 \%$ ). Subsequent to genotyping resistance interpretation algorithm, one major (M46L) and two accessory (N88D, L89V) PIs mutations in the protease region while four NRTI (D67T, K70R/Q, M184V and T215F) and four NNRTI (V108T, E138A, V179I and Y181C) mutations in the reverse transcriptase region were observed. The present study concludes circulation of multiple subtypes of HIV-1 among IDUs and a continuous disease surveillance coupled with delineation of disease risk factors may provide a crucial insight into HIV prevention and treatment which could substantially curtail HIV epidemics in IDUs.
\end{abstract}

\author{
Article Information \\ Received 03 January 2020 \\ Revised 24 January 2020 \\ Accepted 30 January 2020 \\ Available online 12 February 2021 \\ Authors' Contribution \\ SY and MFS collected samples. SY \\ performed practical work. TY and \\ NM conceived and designed the study \\ and also supervised the research work. \\ SY and AuR analyzed the data and \\ wrote the manuscript. MZS, AN and \\ $\mathrm{ZT}$ critically reviewed the manuscript. \\ Key words \\ HIV-1, Prevalence, Molecular \\ epidemiology, Circulating subtypes, \\ Drug resistance, Injecting drug users
}

\section{INTRODUCTION}

I njection drug use has a potential influence on human immunodeficiency virus (HIV) transmission and has raised numerous HIV epidemics worldwide (Conrad et al., 2015; Mirzoyan et al., 2013; Paraskevis et al., 2011; Strathdee et al., 2010). According to world health organization (WHO), out of an estimated 15 million injecting

\footnotetext{
Corresponding author: tahiryaqub@uvas.edu.pk 0030-9923/2021/0002-0563 \$ 9.00/0

Copyright 2021 Zoological Society of Pakistan
}

drug users (IDUs), $>3$ million (20\%) are those living with active HIV infection around the globe. Injecting drug users account for approximately $10 \%$ of HIV infections counting up to $15.5 \%$ in East and Southern Africa and $30 \%$ in other countries. HIV infection was reported in $120(81 \%)$ of the 148 countries in which $20-40 \%$ HIV prevalence was associated with injecting drug users in most of the Asian countries (Mathers et al., 2008). As Asian country, Pakistan is an HIV epidemic country and was considered to be a low prevalence country however in the view of recent increase in concentrated epidemics of acquired immune deficiency syndrome (AIDS) with 
passage of time; it is now in the group of "countries in transition" (Yousaf et al., 2011). Since 1987, the first HIV case in Pakistan (Khanani et al., 1988), the number of HIV cases has been steadily increased among population engaging in high risk practices (Yousaf et al., 2011). These risk factors, particularly the practice of injecting drug use put the Pakistani population at a high risk in spread of HIV infection, especially among injecting drug users (IDUs) (Samo et al., 2013).

HIV is an RNA virus with $9.2 \mathrm{~kb}$ size genome size. It is classified in the genus Lentivirus within the family Retroviridae (King et al., 2018). HIV-1 poses wide genetic variability which is represented by four major groups (M, $\mathrm{N}, \mathrm{O}$, and $\mathrm{P}$ ) and of these $\mathrm{M}$ group is further classified into nine subtypes (A, B, C, D, F, G, H, J, and $\mathrm{K}$ ) and many circulating recombinant forms (CRFs), highlighting undergo an evolution of HIV-1 in the population (Tongo et al., 2016). Currently, there are $>98 \mathrm{CRFs}$ around the globe and in Asian countries HIV-1 subtypes A, B, C, D and G with multiple CRFs are circulating widely (Sarker et al., 2008). Such high genetic diversity reflects complexity of molecular epidemiology of virus within population. Characteristics of HIV-1 variants have an impact on infection transmission, diagnostic aspects, antiretroviral drug efficiency and vaccine development efforts (Kline et al., 2019; Zanini et al., 2015).

HIV genome contains several genes from which pol codes for the viral enzymes reverse transcriptase (RT), integrase (IN) and protease (PR); functionally important for virus replication (Fernandes et al., 2016) and occurrence of substitutions in these regions of $\mathrm{pol}$ protein correspond to subtype differentiation and antiretroviral drug resistance (Nagata et al., 2017; Abram et al., 2010). The survival fitness of these emerging variants is attributed to mutations in its genome for host adaptation that enable them to evade immune system of the host. Such mutations may have much influence in drug resistance pattern and may cause halts in antiretroviral drug therapy (ART) for the treatment of HIV infection (Little et al., 2002; Wallis et $a l ., 2010)$. Therefore, it is always problematic to develop an efficient prophylactic intervention using same class of drugs. Along with occurrence of mutations, the genomic variability of HIV in terms of distribution of different subtypes and CRFs raised concerns about drug efficacy and enforcing to insight the susceptibility pattern of those drugs being administrated in population in which various HIV-1 subtypes and CRFs are circulating.

Owing the circulation of different HIV-1 subtypes and CRFs, several studies have highlighted increasing number of HIV-1 variants among infected individuals (da Guarda Reis et al., 2017). In the past, several studies have been conducted to estimate the HIV-1 prevalence in the general population of Pakistan, however; information related molecular epidemiology of currently prevalent subtypes and CRFs among IDUs is scarce. Although HIV-1 prevalence in IDUs has been investigated in most of cities of different provinces, including Sindh, KPK and Baluchistan, and very few cities of Punjab province, but to best of author's knowledge this first ever study to estimate the prevalence of HIV-1 and its genotyping in IDUs in Lahore. Therefore, the aim of the current study was to comprehensively estimate the prevalence of HIV-1, molecular epidemiology of HIV1 subtypes and CRFs and drug resistance pattern in IDUs of Lahore because of the high ratio of usage of injecting drugs and more probable to be an occurrence of HIV-1 prevalence in this population. This information would be helpful to better understand the HIV-1 epidemiology and drug resistance pattern in IDUs and could be associated with genetic evolution and foundation in anticipating the scope and effectiveness of ART in IDUs.

\section{MATERIALS AND METHODS}

\section{Ethical statement}

This study was carried out in accordance with the recommendations of ethical committee and all essential procedures for sampling were taken after approval by Institutional Review Committee of Institute of Public Health, Lahore vide letter \# IRC: 41/17.

\section{Sample collection and HIV-1 detection}

Under this cross sectional study, 201 plasma samples were collected from people who inject drug (PWID) from different location of Lahore city, Pakistan during February 2017-October 2017. All subjects were male. All participants supplied written informed consent for specimen collection and subsequent analyses. A questionnaire was designed to record of demographic information such as age, marital status, level of education and history of injecting drug use practice. Samples were initially screened using HIV antigen/antibody Combo test (Alere. Determine TM HIV US) according to manufacturer's instruction and interpreted. The screening test had potential to detect both antibodies and antigen simultaneously. In this test antigen is exclusive to HIV type 1, while the antibodies may correspond to either HIV-1 or HIV-2. Besides, HCV surface antigens test was also conducted using RAPID ICT test kit (One-step Hepatitis C Virus Test, Alere, Cat. No 02FK10) was used according to manufacturer's instructions. After initial screening, from HIV-1 antigen positive samples, the viral RNA was extracted using QIAamp DSP RNA Mini Kit (Qiagen, Germany) according to manufacturer's instructions. The pol gene (1084 bp) of HIV-1 was amplified using one-step reverse transcriptase 
polymerase chain reaction (RT-PCR), High-Fidelity Taq polymerase SuperScript III (Life Technologies, USA) in the reverse transcriptase (RT)-nested polymerase chain reaction according to previously described protocol (Zhou et al., 2011). Amplified PCR products were further purified and sequenced by Sanger sequencing method using both reverse and forward primers (Applied Biosystems Prism 310 Genetic Analyzer).

\section{Subtyping classification and phylogenetic analysis}

The under-study sequences were examined for subtype determination using REGA HIV-1 Subtyping Tool (Version 3.0). Moreover, subtyping of under study sequences was further confirmed using jumping profile Hidden Markov Model (jpHMM) available online. Afterward, the obtained sequences were aligned with the reference sequences using ClustalW method in BioEdit software (Hall, 1999). Phylogenetic tree was constructed using neighbor-joining method and Kimura-two parameter model with general time reversible, gamma distribution and invariants nucleotide sites calculated on 1000 bootstraps replication in MEGA 6.0 software (Tamura et al., 2013). All of the mplified sequences from the study were submitted in the GenBank and accessible with accession numbers MN410946-MN410971.

\section{Estimation of antiretroviral drug resistance}

Initially, the quality of sequences was assessed using Calibrated Population Resistance (CPR) tool version 6.0 (http://cpr.stanford.edu/cpr.cgi) and removed those sequences that did not pass the quality criteria. To investigate the presence of transmitted drug resistance mutations (TDRMs), genotyping resistance interpretation algorithm was employed using protease inhibitor (PI), non-nucleoside reverse transcriptase inhibitor (NNRTI) and nucleoside reverse transcriptase inhibitor (NRTI) drugs available in Stanford HIV database.

\section{Statistical analysis}

To investigate possible association between categorical variables (demographic particulates) and HIV1 positivity or negativity IBM SPSS statistics (version 21.0) was used. A level of $p<0.05$ was considered as statistically significant.

\section{RESULTS}

\section{HIV prevalence}

Alere HIV Combo test showed detection of 49 HIV positive samples $(24.37 \%$; $95 \%$ CI: $18.96-30.76)$. These included either detection of antigen alone $(\mathrm{n}=26,50.03 \%$; 95\% CI: 39.38-53.06), and for both antigen and antibodies
( $\mathrm{n}=23,46.94 \% ; 95 \%$ CI: 33.7-60.62). Cumulatively, a significant association of HIV occurrence was observed in individuals having $\mathrm{HCV}$ infection $(36.84 \%$; $95 \% \mathrm{CI}$ : 28.55-45.99; $\mathrm{p}<0.0001$ ) followed by individuals involved in practices of shared injection equipment $(21.17 \%$; $95 \%$ CI: 25.07-40.21; $<<0.0001)$, used syringes $(30.2 \% ; 95 \%$ CI: 23.4-37.99; $\mathrm{p}=0.0016)$, sex with PWID (37.78\%; 95\% CI: 25.11-52.37; $\mathrm{p}=0.002$ ) and those with an age between 30-39 years $(27.17 \%$; 95\% CI: 19.13-37.04; $\mathrm{p}=0.039$ ). Between other univariates the association was non-significant such as single/divorced subjects (28.12\%; 95\% CI: 19.91-41.77, $\mathrm{p}=0.187$ ), subjects with a no formal education (26.92\%; 95\% CI: 20.04-35.13, $\mathrm{p}=0.256)$ and those lived as street dwellers/beggars $(25.58 \% ; 95 \% \mathrm{CI}$ : 18.83-33.74, $\mathrm{p}=0.596$ ). The Cramer's V statistical test revealed a strong and very desirable association of HIV occurrence in individuals with $\mathrm{HCV}(0.33)$, moderate strong and desirable association of HIV occurrence in individuals having shared syringe equipment practice (0.285), moderate and acceptable association of HIV occurrence in individuals between 30-39 years of age (0.225), having practice of used syringe (0.22) and having sex with PWID (0.201), very weak and not generally acceptable association of HIV occurrence was observed in individuals lived single (0.093) and individuals with lack of formal education (0.08), whereas, no association of HIV occurrence was observed in individuals were homeless and lived as street dwellers/beggars (0.038) (Table I).

\section{Subtyping and phylogenetic analysis}

Of these 49 Alere HIV Combo test-HIV positive samples, 26 antigen positive samples were amplified in both first and second round of RT-PCR. Subsequently, substantial analysis of genotyping, phylogenetic and drug resistance analysis was done. Essential analysis for subtyping classification categorized the under-study HIV1 sequences into three HIV-1 subtypes (A, C and G) and a circulating recombinant form (02_AG). Cumulatively, subtype A was found to be predominant $(46.15 \%)$ followed by 02_AG CRFs (23.08\%), subtype C (19.23\%) and subtype $\mathrm{G}(11.54 \%)$. The pol gene-based phylogenetic analysis clustered study sequences into four distinct clades representing subtype $A(n=12), C(n=5), G(n=3)$ and 02 AG CRFs $(n=6)$. Sequences representing subtype A were clustered with HIV sequences originating from Pakistan (JN620529, JN620500 and JN620510) and Uganda (AY803472), 02_AG CRFs sequences were clustered with African originated sequence (AY371134), subtype $\mathrm{C}$ sequences were clustered with Indian (AF067155) and Japanese (AB023804) originated sequences and subtype G sequences were clustered with HIV sequence originating from Singapore (EU715229) (Fig. 1). 
Table I. Demographic characterization and risk factor analysis of HIV-1 infection among injecting drug users.

\begin{tabular}{|c|c|c|c|c|c|c|c|c|}
\hline Risk Factors & Total no. & Positive & Percentage & $95 \% \mathrm{CI}$ & Odd ratio & Risk ratio & p value & Cramer's V-value \\
\hline $18-29$ & 68 & 15 & 22.06 & $13.85-33.26$ & 0.423 & 0.581 & $0.039 *$ & $0.225^{\mathrm{c}}$ \\
\hline $30-39$ & 92 & 25 & 27.17 & $19.13-37.04$ & & & & \\
\hline$>40$ & 41 & 9 & 21.95 & $12-36.7$ & & & & \\
\hline Married & 137 & 29 & 22.63 & $15.16-28.75$ & 0.636 & 0.713 & $0.187^{\mathrm{NS}}$ & $0.093^{\mathrm{d}}$ \\
\hline Single/Divorced & 64 & 19 & 28.12 & $19.91-41.77$ & & & & \\
\hline Some formal education & 71 & 14 & 19.72 & $12.13-30.42$ & 0.667 & 0.732 & $0.256^{\mathrm{NS}}$ & $0.08^{\mathrm{d}}$ \\
\hline Illiterate & 130 & 35 & 26.92 & $20.04-35.13$ & & & & \\
\hline Yes & 143 & 46 & 32.17 & $25.07-40.21$ & 8.694 & 6.219 & $<0.0001 * * *$ & $0.285^{\mathrm{b}}$ \\
\hline No & 58 & 3 & 5.2 & $1.87-14.85$ & & & & \\
\hline New & 52 & 4 & 7.7 & $3.03-18.17$ & 0.202 & 0.263 & $0.0016^{* *}$ & $0.22^{\mathrm{c}}$ \\
\hline Used & 149 & 45 & 30.2 & 23.4-37.99 & & & & \\
\hline Yes & 45 & 17 & 37.78 & $25.11-52.37$ & 0.401 & 0.538 & $0.02 *$ & $0.201^{\mathrm{c}}$ \\
\hline No & 63 & 9 & 9.52 & $7.71-24.98$ & & & & \\
\hline Don't know & 93 & 23 & 24.73 & $17.08-34.38$ & & & & \\
\hline Yes & 114 & 42 & 36.84 & $28.55-45.99$ & 6.667 & 4.578 & $<0.0001 * * *$ & $0.33^{\mathrm{a}}$ \\
\hline No & 87 & 7 & 8.04 & $3.95-15.69$ & & & & \\
\hline $\begin{array}{l}\text { Homeless/street dwell- } \\
\text { ers/beggars }\end{array}$ & 129 & 33 & 25.58 & $18.83-33.74$ & 1.203 & 1.151 & $0.596^{\mathrm{NS}}$ & $0.038^{\mathrm{e}}$ \\
\hline Jobless & 72 & 16 & 22.22 & $14.17-33.09$ & & & & \\
\hline Grand total & 201 & 49 & 24.37 & $18.96-30.76$ & & & & \\
\hline
\end{tabular}

Note: *, significant $(p<0.05)$; **, high significant $(p<0.01) ; * * *$, very high significant $(p<0.001)$; NS, non-significant $(p>0.05)$; a, strong and very desirable association; $b$, moderately strong and desirable association; $c$, moderate acceptable association; $d$, very weak and not generally acceptable association; e, no association

Table II. Major and minor mutations in protease (PR) gene and reverse transcriptase (RT) gene of under-study HIV-1 sequences.

\begin{tabular}{|c|c|c|c|c|c|}
\hline \multirow[t]{2}{*}{ HIV-1 sequences } & \multirow[t]{2}{*}{ Subtypes } & \multicolumn{2}{|c|}{ Protease gene } & \multicolumn{2}{|c|}{ Reverse transcriptase (RT) gene } \\
\hline & & PIs major & PIs accessory & $\begin{array}{l}\text { Nucleoside Reverse Tran- } \\
\text { scriptase Inhibitors (NRTIs) }\end{array}$ & $\begin{array}{l}\text { Non-nucleoside Reverse Tran- } \\
\text { scriptase Inhibitors (NNRTIs) }\end{array}$ \\
\hline PK/LHR/IDU/05 MN410946 & $\mathrm{C}$ & None & None & $\mathrm{T} 215 \mathrm{~F}$ & None \\
\hline PK/LHR/IDU/119 MN410947 & $\mathrm{C}$ & None & None & $\mathrm{T} 215 \mathrm{~F}$ & None \\
\hline PK/LHR/IDU/13 MN410955 & A & None & None & $\mathrm{T} 215 \mathrm{~F}$ & E138A \\
\hline PK/LHR/IDU/122 MN410956 & A & None & None & None & E138A \\
\hline PK/LHR/IDU/156 MN410950 & $\mathrm{C}$ & M46L & None & None & None \\
\hline PK/LHR/IDU/23 MN410951 & 02_AG & None & L89V & None & None \\
\hline PK/LHR/IDU/139 MN410968 & 02_AG & None & L89V & $\mathrm{T} 215 \mathrm{~F}$ & None \\
\hline PK/LHR/IDU/46 MN410952 & $\mathrm{G}$ & None & None & None & V179I \\
\hline PK/LHR/IDU/22 MN410953 & G & None & None & $\mathrm{T} 215 \mathrm{~F}$ & V179I \\
\hline PK/LHR/IDU/172 MN410949 & $\mathrm{C}$ & M46L & None & None & None \\
\hline PK/LHR/IDU/49 MN410954 & G & None & None & D67T, K70R, M184V & V108I, Y181C \\
\hline PK/LHR/IDU/140 MN410962 & A & None & N88D & None & None \\
\hline PK/LHR/IDU/176 MN410964 & A & None & None & $\mathrm{T} 215 \mathrm{~F}, \mathrm{~K} 70 \mathrm{Q}$ & None \\
\hline PK/LHR/IDU/56 MN410965 & A & None & None & $\mathrm{T} 215 \mathrm{~F}$ & E138A \\
\hline PK/LHR/IDU/15 MN410970 & 02_AG & None & None & $\mathrm{T} 215 \mathrm{~F}$ & None \\
\hline
\end{tabular}




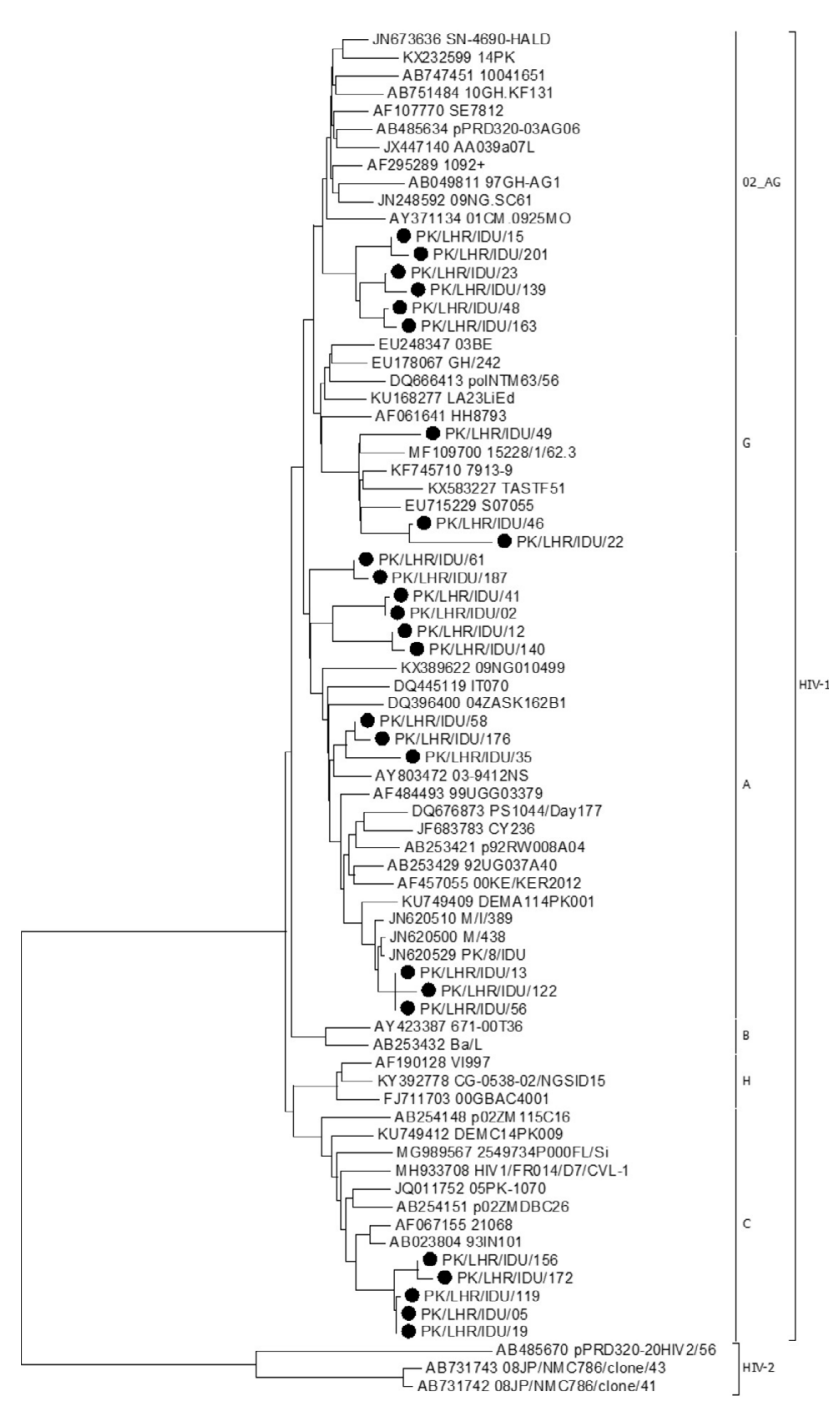

Fig. 1. Based on pol gene, the phylogenetic analysis was constructed using studied HIVs and previously characterized strains representing different subtypes originating from the globe. The phylogeny tree was constructed using neighbor-joining method in MEGA version 6 software. The under-study HIV strains are highlighted as black circle.

\section{Antiretroviral resistance pattern}

Cumulatively, the drug resistance analysis showed one major (M46L) and two accessory (N88D, L89V) PI mutations in protease region while four major NRTI mutations (D67T, K70R/Q, M184V and T215F) and four NNRTI (V108T, E138A, V179I and Y181C) were observed in reverse transcriptase region of pol gene. Among PIs, TPV/r showed the highest susceptibility level (100\%) while NFV (19.23\%) presented highest resistance level as compared to ATV/r (11.54\%), SQV/r (11.54\%) and FPV/r (7.69\%) (Table II). Within NRTIs class, ABC showed the highest susceptibility level (100\%) followed by 3TC, AZT, D4T, DDI, FTC (92.3\%), whereas, a highest resistance level was observed against TDF (30.76\%). Within NNRTIs class, NVP showed highest susceptibility level (100\%) followed by DOR and EFV (92.3\%) while highest resistance level was observed against ETR and RPV (15.38\%) (Table II).

\section{DISCUSSION}

The current study revealed a high risk of HIV occurrence in the individuals involved in practice of shared injection equipment and injected previously used syringe because injection drug use is a potential source of HIV transmission among IDUs (Degenhardt et al., 2017; Stone et al., 2018). This is because, HIV may remain viable in the contaminated syringe for several weeks which has become a potential source of HIV transmission (Kaplan and Heimer, 1992). Most studies have revealed that the occurrence of HIV in IDUs is likely to be linked to practices of injecting with previously used syringe and/or borrowed from another PWID. The transmission of HIV through sharing syringes is a proficient route of infection transmitting (Ball et al., 2019; Conrad et al., 2015; Stone et al., 2018). There have been many examples of very rapid spread of the HIV1 via shared syringe practices among PWIDs in resource rich and poor settings (Des Jarlais et al., 2016; Rhodes et al., 2002). Overall, 24.37\% HIV prevalence was observed herein in IDUs in Lahore city which is slightly higher than other cities observed in previous studies such as $23 \%$ in Karachi, 19.6\% in Sukkur and 18.3\% in Hyderabad (Altaf et al., 2009; Bokhari et al., 2007). The practice of injecting drug use is considered serious risk factor that could put the country in danger of facing a rapid spread and increase of HIV-1 infection. Although Pakistan is a low HIV prevalence country, however, the IDUs are playing a vital role in HIV transmission (Strathdee et al., 2010). Since the first HIV epidemic among PWIDs in Larkana (Shah et al., 2004), HIV-1 has now become well established in PWIDs across the country and despite of various precautionary efforts, the epidemics have relatively expanded among PWIDs with the passage of time (Ali et al., 2017). A strong association was also observed in PWID involved in sexual activities because after sharing needles the major route of HIV transmission is sexual transmission for possible spread of disease among population of large geography (Ball et al., 2019; Conrad et al., 2015; Stone et al., 2018). The tendency for rapid transmission of HIV-1 between those IDUs involved in sexual activities has become a hallmark of epidemics in Pakistan (Strathdee et al., 2010).

In the current study, a high HIV prevalence was 
observed in PWIDs aged 30-39 years which are in agreement of previous study where high HIV prevalence was observed in middle aged individuals (Kooij et al., 2016). Overall, an estimated 5 million young PWID aged 25-35 years were living with HIV and accounted for new HIV infections globally (Feng et al., 2014; Yu et al., 2016). The comparable trend was also found in a previous study where rate of HIV incidence was significantly higher in middle-aged PWIDs (30-40 years) than other age groups (Hakre et al., 2015). The possible reason could be that middle-age individuals are likely to be involved in active sexual life and drugs use practices as compared to young and old PWIDs. Furthermore, a strong association of HIV occurrence was observed in those PWIDs with coinfection of HCV. This is not intersecting because sharing of equipment used for IDUs causes substantial disease burden and such practices of sharing needles and injecting previously used syringe are also a main source of HCV transmission and epidemics not only in PWIDs but also among general population (Eckhardt et al., 2017; Tseng et al., 2007).

Besides the estimation of HIV-1 prevalence, genetic diversity of HIV-1 revealed the circulation of three subtypes (A, G, C) and a CRFs (02_AG) among IDUs. To best of our knowledge, this is the first ever study to explore different HIV-1 subtypes and CRFs circulating in IDUs in Lahore. HIV-1 Subtyping is crucial to understand genetic evolution of circulating HIV-1 isolates in the world (Pond et al., 2009) and, pol gene of HIV-1 is an important marker to accurately delineate HIV-1 genetic diversity (Cantão et al., 2018; Gonzales et al., 2001; HernandezSanchez et al., 2018; Song et al., 2018). The identification of different HIV-1 subtypes and recombinant form within specific population within same region highlights its propensity to be a highly mutable virus, therefore, time to time molecular epidemiological studies are required to conduct at a much higher resolution in future. Previously irrational use of syringes and frequent sexual contact with another either PWID or normal partner has previously been found associated with the spread of HIV-1 and emergence of subtypes (McAuley et al., 2019). Similar evidences of shared syringes and injecting previously used syringes were also observed in current study.

In a previous study, practice of injecting previously used syringe was also anticipated to influence in emergence of novel HIV-1 subtypes or inter-subtypes and different circulating recombinant forms (Lin et al., 2006; Sarker et al., 2008). Although, findings of this study are in the agreement with the previous published study conducted in Sindh, Pakistan, wherein many HIV-1 subtypes and different inter-subtypes were reported among general population (Chen et al., 2016; Khan et al., 2018; Khanani et al., 2011). However, there is a paucity of information on circulation of subtypes and recombinants forms of HIV-1 in IDUs. Consistence to Los Alamos HIV database and previous studies, the current study revealed subtype A as abundant HIV-1 subtype circulating in IDUs. Such variety of recombinant form (02_AG) evolving from two pure parental subtypes (A and $G$ ) indicates emergence of transmissible and viable variants, enhancing genetic diversity of HIV-1.

The possible explanation of emergence of CRF02 AG (recombinant form) could be due to co-circulation of multiple subtypes (A and $G$ ) in same region (Lahore) and/ or co-infection with multiple subtypes of HIV-1 (Leal et al., 2008; Thomson et al., 2002). It is well-known that there is likely to be a possibility of the emergence of HIV-1 CRFs in specific region where multiple subtypes are circulating at a time (Chen et al., 2012). Noteworthy, the high abundance $(n=6)$ of HIV-1 recombinant form (02_AG) was observed here in rather than the parental subtype $G(n=3)$. An in vivo investigation of HIV-1 recombination has revealed that an increase in the proportion of HIV-1 recombinant genomes may coincide with the loss of parental subtype (Iglesias-Sánchez and López-Galíndez, 2002). Indeed, an increase in the prevalence of CRFs may related to the vanishing of parental subtypes, which are usually found at the low frequency (Sanabani et al., 2006). This could be reason of low frequency of subtype $\mathrm{G}$ prevailing in the field as compared to CRF02_AG. Consistently, in other Asian countries like Malaysia, the HIV-1 epidemic is experiencing a gradual replacement of original/initial predominant parental subtype by CRFs (Lau and Wong, 2013). As a consequence of HIV-1 recombination, the genetic variability may enhance the opportunity of host adaptation for various CRFs following modification in selection pressure. Therefore, these emerging CRFs and other variants may have ability to escape host immune responses (Streeck et al., 2008) and/or develop resistance to antiretroviral drugs (Bennett et al., 2009).

Considering the resistance to antiretroviral drugs, all under-study sequences were associated to relatively low level of resistance to PIs however low-high level of resistance to NRTIs and NNRTIs. Herein, the evidences of only one major (M46L) and one accessory (L89V) mutations in sequences related to PIs suggests that the virus is susceptible to all protease inhibitors. Theses observed findings correspond to previous study reported from Sindh province Pakistan where one major resistance associated substitution was observed in study sequences (Khan et al., 2018). Besides, a low-level to high-level drug resistance to TDF, ETR and RPV was also observed due to occurrence of few mutations against the potential sensitivity of NRTIs (T215F, D67T, K70R/Q, M184V) and NNRTIs (E138A, 
V179I, V108I, Y181C). Such mutations have deleterious impact on the susceptibility of antiretroviral drug and may create enormous obstacles to AIDS first-line therapy around the globe (Girard et al., 2006). Another study claimed minor mutations with non-significant impact in RT region of HIV-1 pol gene (Gatanaga et al., 2010; Khan et al., 2016; Shah et al., 2011). Low level of drug resistance in infected population of Punjab is satisfactory and, combination of PIs with NRTIs and NNTRIs, could be continued to treat affected population. Therefore, more studies should be conducted to monitor the trends in mutations so that necessary interventions could be applied in terms of change in regimens immediately for effective treatment and subsequent control of infection in the future.

\section{CONCLUSION}

Current study concluded the extreme genetic heterogeneity of HIV-1 strains prevailing in IDUs and highlighted the significance of continuous monitoring the molecular epidemiology of HIV for the better control of epidemics. Findings of present study emphasize on more focused and intensive awareness programs for safe injection practices throughout the country, especially among IDUs. Local officials could possibly use subtype prevalence data coupled with the demographic details and other molecular analysis to identify on-going HIV-1 transmission and implementation of a tailored combination of interventions for the substantial effect on local HIV epidemic trajectories.

\section{ACKNOWLEDGMENT}

The current study was carried out under the project of Punjab AIDS Control Programs (PACP), Primary and Secondary Health Care Department, Government of Punjab, Pakistan. We would like to thank the team leader and staff members of Institute of Public Health (IPH) Lahore for their help in collecting surveillance information and providing necessary laboratory facilities.

Statement of conflict of interest

The authors have declared no conflict of interest.

\section{REFERENCES}

Abram, M.E., Ferris, A.L., Shao, W., Alvord, W.G. and Hughes, S.H., 2010. Nature, position, and frequency of mutations made in a single cycle of HIV-1 replication. J. Virol., 84: 9864- 9878. https:// doi.org/10.1128/JVI.00915-10

Ali, M., Nadeem, M., Numan, M., Khalil, A.T.,
Maqbool, K., Yousaf, M.Z., Shinwari, Z.K. and Idrees, M., 2017. Thirty years of HIV in Pakistan: a systematic review of prevalence and current scenario. Future Virol., 12: 609-623. https:/www. futuremedicine.com/doi/10.2217/fvl-2017-0009. https://doi.org/10.2217/fvl-2017-0009

Altaf, A., Saleem, N., Abbas, S. and Muzaffar, R., 2009. High prevalence of HIV infection among injection drug users (IDUs) in Hyderabad and Sukkur, Pakistan. J. Pak. med. Assoc., 59: 136-140. https:// www.ncbi.nlm.nih.gov/pubmed/19288936.

Ball, L.J., Puka, K., Speechley, M., Wong, R., Hallam, B., Wiener, J.C., Koivu, S. and Silverman, M.S., 2019. Sharing of injection drug preparation equipment is associated with HIV infection: A cross-sectional study. J. Acquir. Immune Defic. Syndr., 81: e99-e103. https://doi.org/10.1097/ QAI.0000000000002062

Bennett, D.E., Camacho, R.J., Otelea, D., Kuritzkes, D.R., Fleury, H., Kiuchi, M., Heneine, W., Kantor, R., Jordan, M.R. and Schapiro, J.M., 2009. Drug resistance mutations for surveillance of transmitted HIV-1 drug-resistance: 2009 update. PLoS One, 4: e4724. https://doi.org/10.1371/journal. pone.0004724

Bokhari, A., Nizamani, N.M., Jackson, D.J., Rehan, N.E., Rahman, M., Muzaffar, R., Mansoor, S., Raza, H., Qayum, K., Girault, P., 2007. HIV risk in Karachi and Lahore, Pakistan: an emerging epidemic in injecting and commercial sex networks. Int. J. Std. Aids, 18: 486- 492. https://doi. org/10.1258/095646207781147201

Cantão, N.M., de Almeida, L.F., Wolf, I.R., Almeida, R.O., de Almeida Cruz, A.A., Nunes, C., Barbosa, A.N., Valente, G.T., Pardini, M.I.d.M.C. and Grotto, R.M.T., 2018. HIV Reverse transcriptase and protease genes variability can be a biomarker associated with HIV and hepatitis B or C coinfection. Sci. Rep., 8: 8280. https://doi.org/10.1038/s41598018-26675-Z

Chen, Y.J., Lee, C.M., Chen, M., Chuang, S.Y., Liu, H.F., Wong, W.-W., Lin, Y.H., Tsai, H.C., Wang, J.H. and Chen, Y.M.A., 2012. Molecular epidemiology of HIV-1 infection in Taiwan from 2005 to 2008: further spread of CRF07_BC and emergence of CRF07_BC/subtype B dual infection. J. Acquir. Immune. Defic. Syndr., 59: 438-446. https://doi. org/10.1097/QAI.0b013e3182454ea3

Chen, Y., Hora, B., DeMarco, T., Shah, S.A., Ahmed, M., Sanchez, A.M., Su, C., Carter, M., Stone, M. and Hasan, R., 2016. Fast dissemination of new HIV-1 CRF02/A1 recombinants in Pakistan. PLoS 
One, 11: e0167839. https://doi.org/10.1371/journal. pone. 0167839

Conrad, C., Bradley, H.M., Broz, D., Buddha, S., Chapman, E.L., Galang, R.R., Hillman, D., Hon, J., Hoover, K.W. and Patel, M.R., 2015. Community outbreak of HIV infection linked to injection drug use of oxymorphone-Indiana, 2015. Morb. Mortal. Wkly. Rep., 64: 443- 444. https://www.ncbi.nlm.nih. gov/pmc/articles/PMC4584812/.

da Guarda Reis, M.N., Bello, G., Guimarães, M.L. and Stefani, M.M.A., 2017. Characterization of HIV1 CRF90_BF1 and putative novel CRFs_BF1 in Central West, North and Northeast Brazilian regions. PLoS One, 12: e0178578. https://doi.org/10.1371/ journal.pone. 0178578

Degenhardt, L., Peacock, A., Colledge, S., Leung, J., Grebely, J., Vickerman, P., Stone, J., Cunningham, E.B., Trickey, A. and Dumchev, K., 2017. Global prevalence of injecting drug use and sociodemographic characteristics and prevalence of HIV, HBV and HCV in people who inject drugs: a multistage systematic review. Lancet Glob. Hlth., 5: e1192- e1207. https://doi.org/10.1016/S2214109X(17)30375-3

Des Jarlais, D.C., Kerr, T., Carrieri, P., Feelemyer, J. and Arasteh, K., 2016. HIV infection among persons who inject drugs: ending old epidemics and addressing new outbreaks. AIDS, 30: 815-826. https://doi. org/10.1097/QAD.0000000000001039

Eckhardt, B., Winkelstein, E.R., Shu, M.A., Carden, M.R., McKnight, C., Des Jarlais, D.C., Glesby, M.J., Marks, K. and Edlin, B.R., 2017. Risk factors for hepatitis $\mathrm{C}$ seropositivity among young people who inject drugs in New York City: Implications for prevention. PLoS One, 12: e0177341. https://doi. org/10.1371/journal.pone.0177341

Feng, L., Li, P., Wang, X., Hu, Z., Ma, Y., Tang, W., Ben, Y., Mahapatra, T., Cao, X. and Mahapatra, S., 2014. Distribution and determinants of non-communicable diseases among elderly Uyghur ethnic group in Xinjiang, China. PLoS One, 9: e105536. https://doi. org/10.1371/journal.pone.0105536

Fernandes, J.D., Faust, T.B., Strauli, N.B., Smith, C., Crosby, D.C., Nakamura, R.L., Hernandez, R.D., Frankel, A.D., 2016. Functional segregation of overlapping genes in HIV. Cell, 167: 1762-1773. e12. https://doi.org/10.1016/j.cell.2016.11.031

Gatanaga, H., Ode, H., Hachiya, A., Hayashida, T., Sato, H. and Oka, S., 2010. Combination of V106I and V179D polymorphic mutations in human immunodeficiency virus type 1 reverse transcriptase confers resistance to efavirenz and nevirapine but not etravirine. Antimicrob. Agents Chemother., 54: 1596-1602. https://doi.org/10.1128/AAC.01480-09

Girard, M.P., Osmanov, S.K. and Kieny, M.P., 2006. A review of vaccine research and development: the human immunodeficiency virus (HIV). Vaccine, 24: 4062-4081. https://doi.org/10.1016/j. vaccine. 2006.02 .031

Gonzales, M.J., Machekano, R.N. and Shafer, R.W., 2001. Human immunodeficiency virus type 1 reversetranscriptase and protease subtypes: classification, amino acid mutation patterns, and prevalence in a northern California clinic-based population. J. Infect. Dis., 184: 998-1006. https://doi.org/10.1086/323601

Hakre, S., Mydlarz, D.G., Dawson, P., Danaher, P.J., Gould, P.L., Witkop, C.T., Michael, N.L., Peel, S.A., Scott, P.T. and Okulicz, J.F., 2015. Epidemiology of HIV among US Air Force Military Personnel, 1996-2011. PLoS One, 10: e0126700. https://doi. org/10.1371/journal.pone.0126700

Hall, T.A., 1999. BioEdit: a user-friendly biological sequence alignment editor and analysis program for Windows 95/98/NT. Nucl. Acids Symp. Ser., [London]: Information Retrieval Ltd., c1979-c2000., pp. 95-98.

Hernandez-Sanchez, P.G., Guerra-Palomares, S.E., Ramirez-GarciaLuna, J.L., Arguello, J.R., Noyola, D.E. and Garcia-Sepulveda, C.A., 2018. Prevalence of drug resistance mutations in protease, reverse transcriptase, and integrase genes of North Central Mexico HIV isolates. AIDS Res. Hum. Retrov., 34: 498-506. https://doi.org/10.1089/aid.2017.0257

Iglesias-Sánchez, M.J. and López-Galíndez, C., 2002. Analysis, quantification, and evolutionary consequences of HIV-1 in vitro recombination. Virology, 304: 392-402. https://doi.org/10.1006/ viro.2002.1657

Kaplan, E.H. and Heimer, R., 1992. A model-based estimate of HIV infectivity via. needle sharing. $J$. Acquir. Immune. Defic. Syndr., 5: 1116-1118. https:// journals.lww.com/jaids/Abstract/1992/11000/A_ Model_Based_Estimate_of_HIV_Infectivity_ via.9.aspx.

Khan, S., Zahid, M., Qureshi, M.A., Mughal, M.N. and Ujjan, I.D., 2018. HIV-1 genetic diversity, geographical linkages and antiretroviral drug resistance among individuals from Pakistan. Arch. Virol., 163: 33-40. https://doi.org/10.1007/s00705017-3564-1

Khan, S., Zehra, F., Zahid, M., Iqbal, A. and Maqsood, N., 2016. Pattern of concentrated HIV epidemic in Pakistan. Pathology, 48: S132. https://www. pathologyjournal.rcpa.edu.au/article/S0031- 
3025(15)00383-9/fulltext. https://doi.org/10.1016/j. pathol.2015.12.356

Khanani, M.R., Somani, M., Rehmani, S.S., Veras, N.M., Salemi, M., Ali, S.H., 2011. The spread of HIV in Pakistan: bridging of the epidemic between populations. PLoS One, 6: e22449. https://doi. org/10.1371/journal.pone.0022449

Khanani, R.M., Hafeez, A., Rab, S. and Rasheed, S., 1988. Human immunodeficiency virus-associated disorders in Pakistan. AIDS Res. Hum. Retrov., 4: 149-154. https://doi.org/10.1089/aid.1988.4.149

King, A.M., Lefkowitz, E.J., Mushegian, A.R., Adams, M.J., Dutilh, B.E., Gorbalenya, A.E., Harrach, B., Harrison, R.L., Junglen, S. and Knowles, N.J., 2018. Changes to taxonomy and the International Code of Virus Classification and Nomenclature ratified by the International Committee on Taxonomy of Viruses (2018). Arch. Virol., 163: 2601-2631. https:// doi.org/10.1007/s00705-018-3847-1

Kline, R.L., Saduvala, N., Zhang, T. and Oster, A.M., 2019. Diversity and characterization of HIV-1 subtypes in the United States, 2008-2016. Annls Epidemiol., 33: 84-88. https://doi.org/10.1016/j. annepidem.2019.02.010

Kooij, K.W., Wit, F.W., Schouten, J., van der Valk, M., Godfried, M.H., Stolte, I.G., Prins, M., Falutz, J. and Reiss, P., 2016. HIV infection is independently associated with frailty in middle-aged HIV type 1-infected individuals compared with similar but uninfected controls. AIDS, 30: 241-250. https://doi. org/10.1097/QAD.0000000000000910

Lau, K.A. and Wong, J.J., 2013. Current trends of HIV recombination worldwide. Infect. Dis. Rep., 5: e4. https://doi.org/10.4081/idr.2013.s1.e4

Leal, É., Silva, W.P., Sucupira, M.C., Janini, L.M. and Diaz, R.S., 2008. Molecular and structural characterization of HIV-1 subtype B Brazilian isolates with GWGR tetramer at the tip of the V3-loop. Virology, 381: 222-229. https://doi. org/10.1016/j.virol.2008.08.029

Lin, H.-H., Shih, Y.-L., Liu, Y.-C., Lee, S.S.-J., Huang, C.-K., Chen, Y.-L., Chin, C., Lai, C.-H., Tsai, H.C. and Guo, Y.-C., 2006. An epidemic of HIV type I CRF07_BC infection among injection drug users in Taiwan. J. Acquir. Immune. Defic. Syndr., 42: 248-255. https://doi.org/10.1097/01. qai.0000214818.80539.da

Little, S.J., Holte, S., Routy, J. P., Daar, E.S., Markowitz, M., Collier, A.C., Koup, R.A., Mellors, J.W., Connick, E. and Conway, B., 2002. Antiretroviraldrug resistance among patients recently infected with HIV. N. Engl. J. Med., 347: 385-394. https://
doi.org/10.1056/NEJMoa013552

Mathers, B.M., Degenhardt, L., Phillips, B., Wiessing, L., Hickman, M., Strathdee, S.A., Wodak, A., Panda, S., Tyndall, M. and Toufik, A., 2008. Global epidemiology of injecting drug use and HIV among people who inject drugs: A systematic review. Lancet, 372: 1733-1745. https://doi.org/10.1016/ S0140-6736(08)61311-2

McAuley, A., Palmateer, N.E., Goldberg, D.J., Trayner, K.M., Shepherd, S.J., Gunson, R.N., Metcalfe, R., Milosevic, C., Taylor, A., Munro, A., 2019. Re-emergence of HIV related to injecting drug use despite a comprehensive harm reduction environment: A cross-sectional analysis. Lancet HIV, 6: e315-e324. https://doi.org/10.1016/S23523018(19)30036-0

Mirzoyan, L., Berendes, S., Jeffery, C., Thomson, J., Othman, H.B., Danon, L., Turki, A.A., Saffialden, R. and Valadez, J.J., 2013. New evidence on the HIV epidemic in Libya: why countries must implement prevention programs among people who inject drugs. J. Acquir. Immune. Defic. Syndr., 62: 577-583. https://doi.org/10.1097/QAI.0b013e318284714a

Nagata, S., Imai, J., Makino, G., Tomita, M., Kanai, A., 2017. Evolutionary analysis of HIV-1 pol proteins reveals representative residues for viral subtype differentiation. Front. Microbiol., 8: 2151. https:// doi.org/10.3389/fmicb.2017.02151

Paraskevis, D., Nikolopoulos, G., Tsiara, C., Paraskeva, D., Antoniadou, A., Lazanas, M., Gargalianos, P., Psychogiou, M., Malliori, M. and Kremastinou, J., 2011. HIV-1 outbreak among injecting drug users in Greece, 2011: A preliminary report. Euro. Surveill., 16: 19962. https://doi.org/10.2807/ese.16.36.19962en

Pond, S.L.K., Posada, D., Stawiski, E., Chappey, C., Poon, A.F., Hughes, G., Fearnhill, E., Gravenor, M.B., Brown, A.J.L. and Frost, S.D., 2009. An evolutionary model-based algorithm for accurate phylogenetic breakpoint mapping and subtype prediction in HIV1. PLoS Comput. Biol., 5: e1000581. https://doi. org/10.1371/journal.pcbi.1000581

Rhodes, T., Lowndes, C., Judd, A., Mikhailova, L.A., Sarang, A., Rylkov, A., Tichonov, M., Lewis, K., Ulyanova, N. and Alpatova, T., 2002. Explosive spread and high prevalence of HIV infection among injecting drug users in Togliatti City, Russia. AIDS, 16: F25-F31. https://doi.org/10.1097/00002030200209060-00002

Samo, R.N., Altaf, A., Agha, A., Pasha, O., Rozi, S., Memon, A., Azam, S., Blevins, M., Vermund, S.H., Shah, S.A., 2013. High HIV incidence among 
persons who inject drugs in Pakistan: greater risk with needle sharing and injecting frequently among the homeless. PLoS One, 8: e81715. https://doi. org/10.1371/journal.pone.0081715

Sanabani, S., Neto, W.K., Kalmar, E.M., Diaz, R.S., Janini, L.M. and Sabino, E.C., 2006. Analysis of the near full length genomes of HIV-1 subtypes B, F and BF recombinant from a cohort of 14 patients in Sao Paulo, Brazil. Infect. Genet. Evol., 6: 368-377. https:// doi.org/10.1016/j.meegid.2006.01.003

Sarker, M.S., Rahman, M., Yirrell, D., Campbell, E., Rahman, A.M., Islam, L.N. and Azim, T., 2008. Molecular evidence for polyphyletic origin of human immunodeficiency virus type 1 subtype C in Bangladesh. Virus Res., 135: 89-94. https://doi. org/10.1016/j.virusres.2008.02.010

Shah, S., Xing, H., Altaf, A., Chen, B., Liao, L., Jia, Y., Vermund, S.H. and Shao, Y., 2011. Antiretroviral drug resistance mutations among treated and treatmentnaive patients in Pakistan: Diversity of the HIV type 1 pol gene in Pakistan. AIDS Res. Hum. Retrov., 27: 1277-1282. https://doi.org/10.1089/aid.2010.0324

Shah, S.A., Altaf, A., Mujeeb, S.A. and Memon, A., 2004. An outbreak of HIV infection among injection drug users in a small town in Pakistan: potential for national implications. Int. J. STD AIDS, 15: 209. https://doi. org/10.1258/095646204322916713

Song, H., Giorgi, E.E., Ganusov, V.V., Cai, F., Athreya, G., Yoon, H., Carja, O., Hora, B., Hraber, P. and RomeroSeverson, E., 2018. Tracking HIV-1 recombination to resolve its contribution to HIV-1 evolution in natural infection. Nat. Commun., 9: 1928. https://doi. org/10.1038/s41467-018-04217-5

Stone, J., Fraser, H., Lim, A.G., Walker, J.G., Ward, Z., MacGregor, L., Trickey, A., Abbott, S., Strathdee, S.A. and Abramovitz, D., 2018. Incarceration history and risk of HIV and hepatitis $\mathrm{C}$ virus acquisition among people who inject drugs: a systematic review and meta-analysis. Lancet Infect. Dis., 18: 1397-1409. https://doi.org/10.1016/S1473-3099(18)30469-9

Strathdee, S.A., Hallett, T.B., Bobrova, N., Rhodes, T., Booth, R., Abdool, R. and Hankins, C.A., 2010. HIV and risk environment for injecting drug users: The past, present, and future. Lancet, 376: 268-284. https://doi.org/10.1016/S0140-6736(10)60743-X

Streeck, H., Li, B., Poon, A.F., Schneidewind, A., Gladden, A.D., Power, K.A., Daskalakis, D., Bazner, S., Zuniga, R. and Brander, C., 2008. Immunedriven recombination and loss of control after HIV superinfection. J. exp. Med., 205: 1789-1796. https:// doi.org/10.1084/jem.20080281
Tamura, K., Stecher, G., Peterson, D., Filipski, A., Kumar, S., 2013. MEGA6: Molecular evolutionary genetics analysis version 6.0. Mol. Biol. Evol., 30: 2725-2729. https://doi.org/10.1093/molbev/mst197

Thomson, M.M., Delgado, E., Herrero, I., Villahermosa, M.L., Vázquez-de Parga, E., Cuevas, M.T., Carmona, R.o., Medrano, L., Perez-Alvarez, L. and Cuevas, L., 2002. Diversity of mosaic structures and common ancestry of human immunodeficiency virus type 1 $\mathrm{BF}$ intersubtype recombinant viruses from Argentina revealed by analysis of near full-length genome sequences. J. Gen. Virol., 83: 107-119. https://doi. org/10.1099/0022-1317-83-1-107

Tongo, M., Dorfman, J.R. and Martin, D.P., 2016. High degree of HIV-1 group M (HIV-1M) genetic diversity within circulating recombinant forms: insight into the early events of HIV-1M evolution. J. Virol., 90: 22212229. https://doi.org/10.1128/JVI.02302-15

Tseng, F.C., O’Brien, T.R., Zhang, M., Kral, A.H., OrtizConde, B.A., Lorvick, J., Busch, M.P. and Edlin, B.R., 2007. Seroprevalence of hepatitis C virus and hepatitis B virus among San Francisco injection drug users, 1998 to 2000. Hepatology, 46: 666-671. https:// doi.org/10.1002/hep. 21765

Wallis, C.L., Mellors, J.W., Venter, W.D., Sanne, I. and Stevens, W., 2010. Varied patterns of HIV-1 drug resistance on failing first-line antiretroviral therapy in SouthAfrica.J. Acquir. Immune. Defic. Syndr., 53:480484. https://doi.org/10.1097/QAI.0b013e3181bc478b

Yousaf, M.Z., Zia, S., Babar, M.E., Ashfaq, U.A., 2011. The epidemic of HIV/AIDS in developing countries; the current scenario in Pakistan. Virol. J., 8: 401. https://doi.org/10.1186/1743-422X-8-401

Yu, W., Wang, L., Han, N., Zhang, X., Mahapatra, T., Mahapatra, S., Babu, G.R., Tang, W., Detels, R. and Zhao, J., 2016. Pre-exposure prophylaxis of HIV: A right way to go or a long way to go? Artif. Cells Nanomed. Biotechnol., 44: 201-208. https://doi.org/1 0.3109/21691401.2014.934458

Zanini, F., Brodin, J., Thebo, L., Lanz, C., Bratt, G., Albert, J. and Neher, R.A., 2015. Population genomics of intrapatient HIV-1 evolution. Elife, 4: e11282. https:// doi.org/10.7554/eLife.11282

Zhou, Z., Wagar, N., DeVos, J.R., Rottinghaus, E., Diallo, K., Nguyen, D.B., Bassey, O., Ugbena, R., WadondaKabondo, N. and McConnell,M.S., 2011.Optimization of a low cost and broadly sensitive genotyping assay for HIV-1 drug resistance surveillance and monitoring in resource-limited settings. PLoS One, 6: e28184. https://doi.org/10.1371/journal.pone.0028184 